\title{
Many More Consumers Not Always Induce Stronger Competition: Weaker Interspecific Competition Despite Higher Species Richness in Secondary Feeding Guild, as Compared to Primary
}

\author{
Jean Béguinot ${ }^{1^{*}}$
}

${ }^{1}$ Université De Bourgogne, 6, Boulevard Gabriel, 21000 Dijon, France.

Author's contribution

The sole author designed, analysed, interpreted and prepared the manuscript.

Article Information

DOI: $10.9734 / A R R B / 2021 / v 36 i 830413$

Editor(s):

(1) Dr Paola Angelini, University of Perugia, Italy.

Reviewers:

(1) Koushik Sadhukhan, Ministry Pf Earth Science, India.

(2) Joji. V. S, University of Science and Technology, India.

(3) Pham Van Dien, Viet Nam National University of Forestry, Viet Nam. Complete Peer review History: https://www.sdiarticle4.com/review-history/72155

Review Article

Received 01 May 2021

Accepted 07 August 2021

Published 13 August 2021

\begin{abstract}
The species functional structuration (specifically in terms of species richness and average intensity of interspecific competition) is widely varying among species communities and this point is now very well documented in literature. But, what about the species functional structuration within the different feeding guilds that coexist in a same local community - in particular the primary and the secondary feeding guilds? Are there significant differences - or not - between them in this respect? This rather fundamental issue does not seem having been addressed yet, at least using appropriate investigative tools. However, a series of recently published case studies, precisely implementing such an adequate investigative approach, now deserves full consideration in this regard and makes the subject of the present review. Substantially, it results from this preliminary survey of the question that marked differences in the patterns of species functional structuration clearly singularize the secondary from the primary feeding guilds, within a same local community. More precisely, a consistent trend seems to arise, highlighting both: (i) a markedly greater species richness and, yet somewhat unexpectedly, (ii) a significantly reduced intensity in interspecific competition within secondary feeding guild as compared to primary. The point is discussed and interpreted as being the consequence of the fact that secondary feeders (typically carnivores) have obviously evolve quite more diversified feeding behaviors than did the primary feeders (typically herbivores).
\end{abstract}


Keywords: Species structuration; community; gastropod; fish; coral reef; abundance unevenness.

\section{INTRODUCTION}

"The more invited guests there are, the tougher the competition for access to the same food table..." This popular adage seems, at first, being based on elementary logic - but indeed would imply, of course, that the size and richness of food table, as well as the own feeding requirements of the various guests, all remain unchanged.

But in the wild, it is at least possible - and perhaps even likely - that the size of the "food table", as well as the guests' feeding-options (and their respective access strategies to shared resource), may variously change according to the numbers of "invited guests". Accordingly, it looks conceivable that the preceding adage might be either verified or contradicted, depending on species assemblages, environmental contexts and any other circumstances. So that, finally, no predicate, intended to be more or less universal, seems likely to be proposed in this regard. Therefore, this point deserves investigation, in particular on a case-by-case basis.

Among the various patterns to be examined in this perspective, one especially interesting one is: what about (i) the species richness and (ii) the average intensity of interspecific-competition, among coexisting feeding guilds within a same local community of species? For example, what about the primary (typically herbivore) and the secondary (typically carnivore) coexisting feeding guilds, in this respect?.

Reef associated assemblages, known as being among the richer and more diversified ecosystem worldwide [1-5], are, for this reason, especially appealing to undertake such a survey.

I propose, hereafter, a brief survey of a series of seven case studies, all of them devoted to reefassociated gastropod or reef-associated fish communities, within which both species richness and interspecific competition are quantified separately in the primary and the secondary feeding guilds. More precisely, in each of these seven case-studies:

(i) The evaluation of the "true" species richness " $\mathrm{S} t$ " of each feeding guild is corrected for the unavoidable risk [6] of under-sampling by implementing a (recently developed) procedure of least-biased extrapolation of the 'species accumulation function' [7-9]. This procedure allows to estimate - on a rational, mathematically consistent basis - the number of species remained unrecorded. Thereby, putting an end to the traditional method of making an arbitrary, or at least "pseudo-rational" choice among the various types of nonparametric estimators proposed in the literature (viz Jackknife of various orders, Chao, etc...), following in that the sound approach first initiated by BROSE et al. [10];

(ii) The average intensity of the interspecific competition within each feeding guild is estimated by considering the so-called "standardized" unevenness "Istr" of the distribution of species abundances, as defined, for example in reference [11]. Indeed, by standardizing the recorded unevenness of species abundance to the level of unevenness of the "broken-stick" theoretical distribution [12,13] computed at the same level of species richness, the standardized unevenness index $I_{\text {str }}$ benefits by the capacity to reliably mirror the average level of interspecific competition, as already suggested by MACARTHUR as soon as 1957 [12]. And further argued in reference [11].

\subsection{A Brief Survey of Both Species Richness and Interspecific competition Intensity within Feeding Guilds, in a series of Reef-Associated Communities}

Seven case-studies are reviewed hereafter, each of them comparing the primary and the secondary feeding guilds as regards:

(i) There numerically extrapolated true species richness $S_{t}$ and

(ii) The standardized unevenness $I_{\text {str }}$ of the distribution of species abundances reflecting, as said above, the average intensity of interspecific competition within each guild.

The couple of parameters $S_{t}$ and $I_{s t r}$ thus highlighting the main features of the species structuration within each guild (as well as within community).

Three case-studies involve Gastropod communities associated to coral-reefs in Indian and Pacific Oceans, namely: along Andaman Island (India) [14], in Mannar Gulf (India) [15], and along Suva Island (Fiji's) [16]: see Fig. 1. 


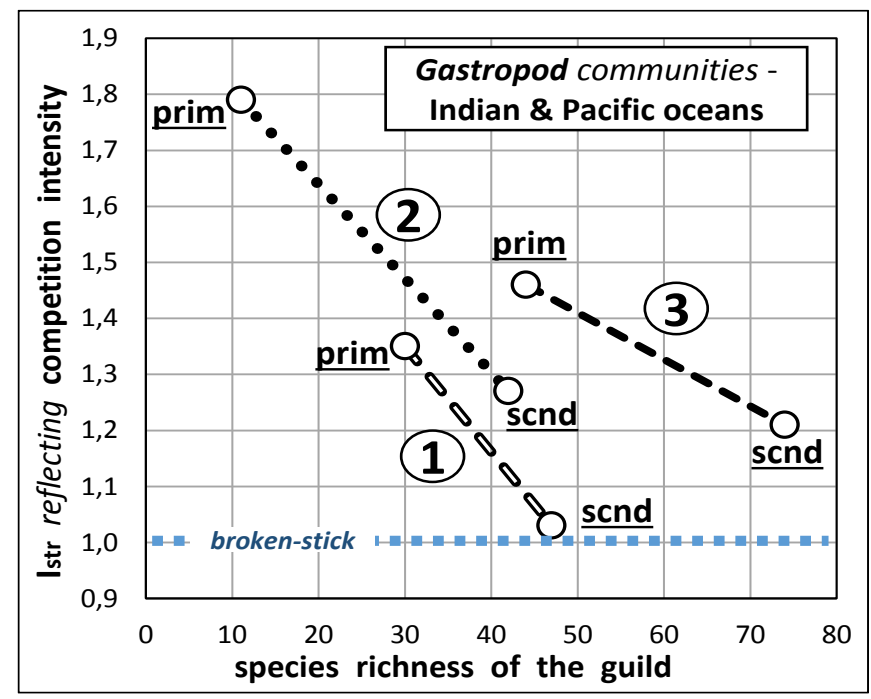

Fig. 1. The species-richness $S_{t}$ and the standardized abundance-unevenness $I_{\text {str }}$ (reflecting the average intensity of interspecific competition) for each of the two main feeding guilds primary feeders "prim" and secondary feeders "scnd"; Three reef-associated Gastropod communities are considered, located along (1) Andaman Island [14], (2) Mannar Gulf (India) [15] and (3) Suva Island (Fiji's) [16]. The trend for the guild of primary consumers to have lower species richness while involving stronger competition intensity than the guild of secondary consumers is common to all three communities

The other four case-studies involve Fish communities associated to coral-reefs in southwest Atlantic Ocean, along Brazilian coast [17] and Indian Ocean, in Indonesia, off Jakarta [18]: see Figs 2 \& 3

Finally, a consistent overall congruence is highlighted between the patterns documented in each of these seven case-studies: the guild of primary consumers has lower species richness while involving stronger competition intensity than the guild of secondary consumers.

\section{DISCUSSION}

To our knowledge, the literature is scarce regarding the comparison of how species are structured within primary and within secondary feeding guilds belonging to the same local community. Only recently, GARCIA-CALLEJAS reports on comparisons between primary and secondary feeders in terms of both the species richness and the as-observed species abundance evenness. But although this work represents a very interesting first step in this regard, two important points deserve to be further explored, in order to be able to reach more reliable assessments:

- The as-observed species richness is often likely to be underestimated more or less strongly and uncontrollably, as duly emphasized by numerous authors, see in particular reference [6]. So that only the least-biased numerical extrapolation of the recorded data can provide acceptably reliable evaluations of the true species richness within a given guild (or community) [7-9]. Note that taking due account of rarer species, which often escape recording, is all the more important that these rare species (beyond their own intrinsic interest) may disproportionately contribute to the functional structuring of communities, as has often been pointed out [19-29]: "rare species are critical for bio-assessment" as quoted in [29].

The degree of unevenness of species abundance distribution is not at all independent of - more precisely, is strongly negatively correlated with - the species richness, as already underlined by numerous authors (see [11] for a review) and by GARCIA-CALLEJAS [30] himself. In fact, it is only the "standardized" unevenness [11] which ought to be considered as relevant - being the part of abundance unevenness which is, by construction, independent of species richness, and, in addition, able to directly account for the average intensity of interspecific competition for shared resource at niches overlaps [11, 12]. 


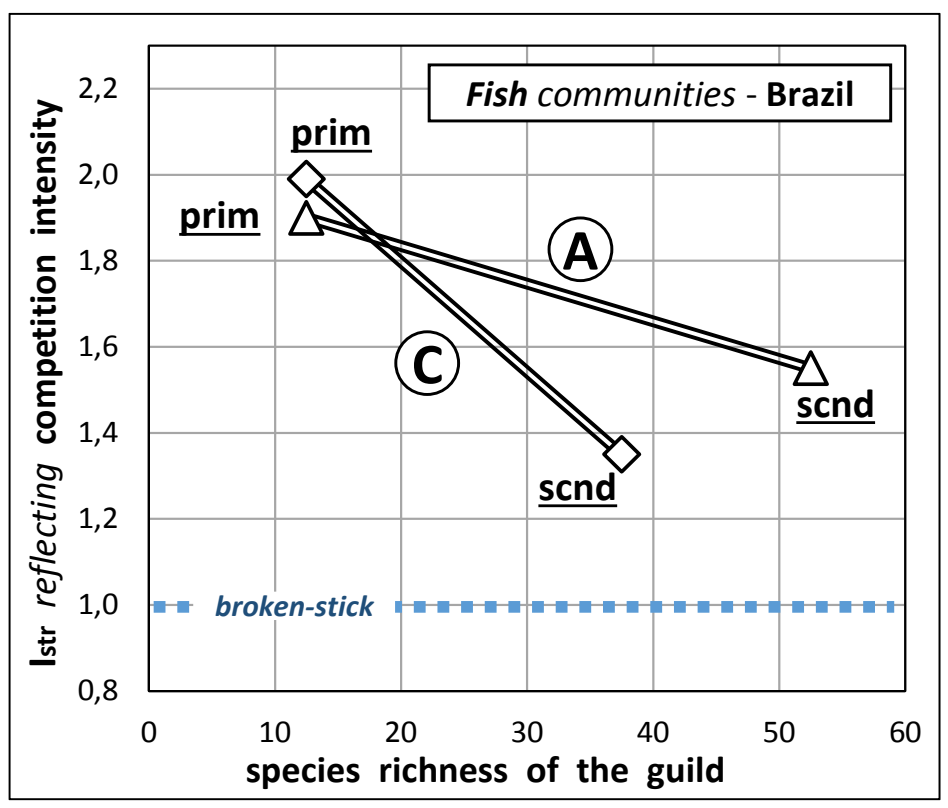

Fig. 2. The species-richness $S_{t}$ and the standardized abundance-unevenness $I_{s t r}$ (reflecting the average intensity of interspecific competition) for each of the two main feeding guilds primary feeders "prim" and secondary feeders "scnd"; Two reef-associated Fish communities, (A) \& (C), are considered, both located on Tamandaré coral-reefs, north-east Brazilian coast

[17]. The trend for the guild of primary consumers to have lower species richness while involving stronger competition intensity than the guild of secondary consumers is common to the both communities

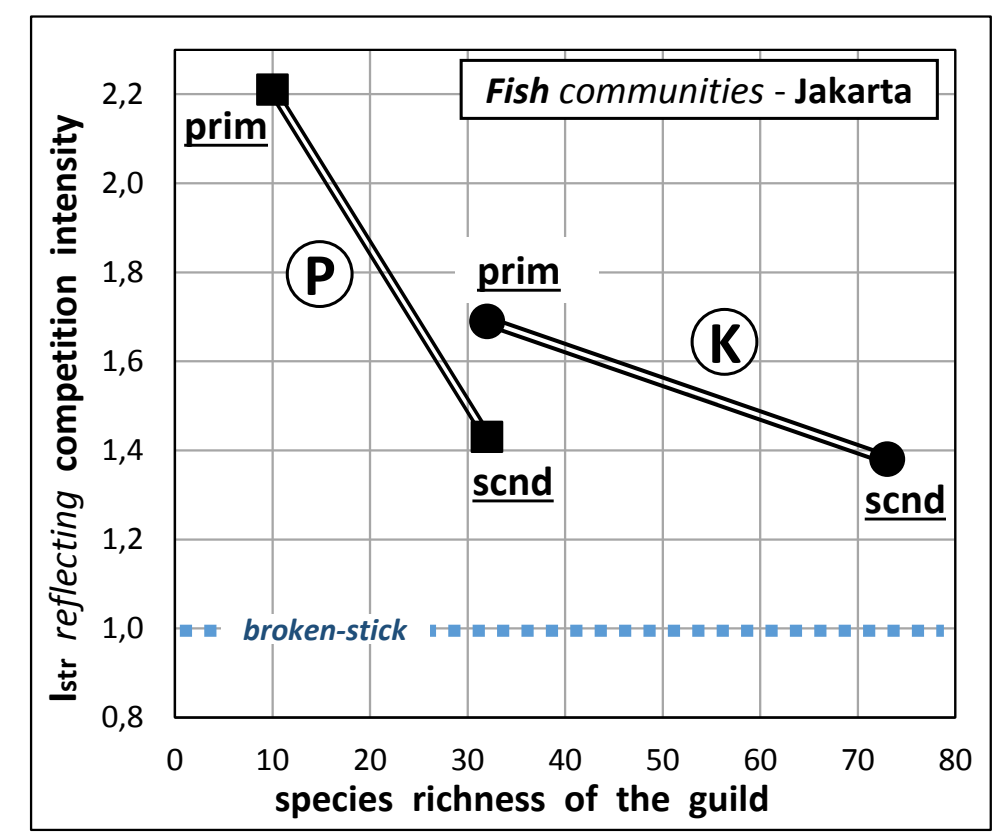

Fig. 3. The species-richness $S_{t}$ and the standardized abundance-unevenness $I_{\text {str }}$ (that mirrors the intensity of interspecific competition) for each of the two main feeding guilds - primary feeders "prim" and secondary feeders "scnd"; Two reef-associated Fish communities are considered, located off Jakarta Bay, respectively at Pari $(P)$ and Kelapa (K) [18]. The trend for

the guild of primary consumers to have lower species richness while involving stronger competition intensity than the guild of secondary consumers is common to both communities, $(\mathrm{P})$ and $(\mathrm{K})$ 


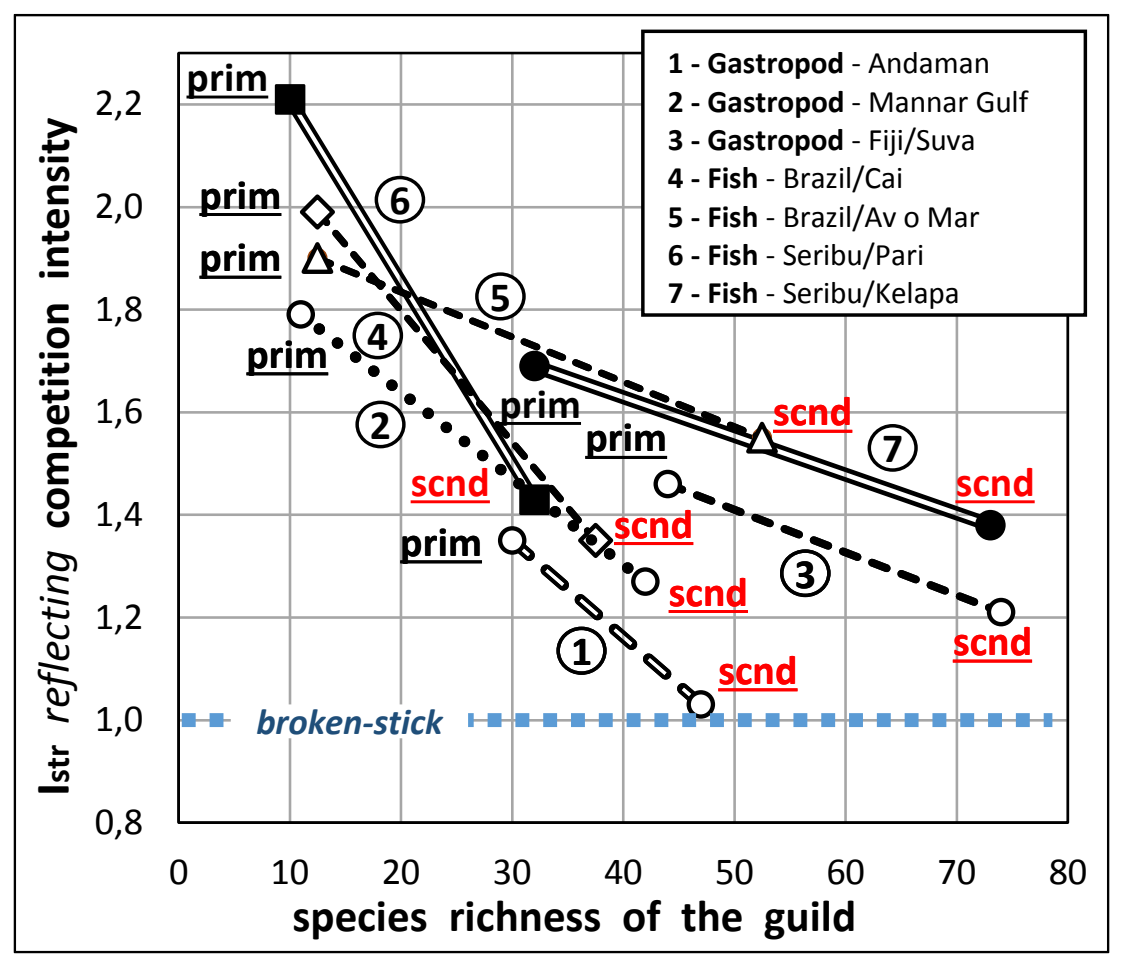

Fig. 4. The species-richness $S_{t}$ and the standardized abundance-unevenness $I_{s t r}$ (that mirrors the average intensity of interspecific competition) for each of the two main feeding guilds primary feeders "prim" and secondary feeders "scnd"; Synthesis of the results issued from the series of seven case-studies

Thus, for both reasons above, the question of how species are structured within primary and secondary feeding guilds - and whether significant difference does exist (or not) in this respect between these two guilds - is a fundamental issue which remained to be considered according to this new perspective.

The review presented above, surveying a series of seven case-studies - each of them treated in a way satisfying both methodological requirements above - provides preliminary answers in this regard. All seven case-studies consistently show similarly contrasted patterns between the primary and the secondary feeding guilds belonging to the same local community. Namely (Fig. 4):

* The secondary feeding guild is consistently and appreciably more species-rich than is the corresponding primary feeding guild;

* The secondary feeding guild consistently shows a lower value of the standardized abundance unevenness $\mathrm{I}_{\text {str }}$ - thus reflecting a weaker average intensity of interspecific competition - than it is the case for the corresponding primary feeding guild.
Which strongly suggests, in turn, that:

- niches diversification among secondary feeders (say, typically carnivores) exceeds what is encountered among primary feeders (say, typically herbivores)

- and, moreover, this greater diversification of niches among secondary feeders does not elicit an increase in the degree of niches overlaps, but, on the contrary, induces a further reduction of these niches overlaps. Thus, likely explaining the attested reduction of interspecificcompetition intensity.

Finally, it does not seem too difficult to speculate on the likely origin of this somewhat unexpected reduction in niches overlaps, despite the multiplication of these niches, which thus characterizes the more species-rich secondary guild. Indeed, secondary feeders (typically carnivores) have obviously evolved a considerably richer diversity in their patterns of feeding behaviors than have done primary feeders (like herbivores). And this wide behavioral diversity is expected to have largely contributed to seriously limiting the niches 
overlaps. And this despite the higher species richness - and thus the correspondingly greater number of associated niches - within the guild of secondary feeders.

However, as much varied as these seven case studies actually are - both taxonomically and geographically - it remains, admittedly, that ample further investigations are necessary to conclude more firmly on this topic. Being understood that the required additional work should be, as far as possible, carried out in compliance with the methodological requirements emphasized above.

\section{CONCLUSION}

The question of how species are structured - in terms of species richness and average intensity of interspecific competition - within primary and secondary feeding guilds respectively - and whether this structuration of species differs significantly between these guilds - did not seem having been relevantly addressed so far. This important question therefore needed dedicated investigations to be undertaken. A series of recently published, case-studies now fulfills this objective and deserved being reviewed globally.

By using appropriate investigating tools (namely, numerical extrapolation of species richness and "standardized" approach of species abundance unevenness, thereby reflecting the intensity of interspecific competition), this series of seven case-studies - briefly reviewed above - finally provides a first enlightenment on this fundamental subject.

\section{ACKNOWLEDGEMENTS}

I acknowledge the fruitful comments of three anonymous Referees.

\section{COMPETING INTERESTS}

Author has declared that no competing interests exist.

\section{REFERENCES}

1. Wells JW. Coral reefs: 609-632; in J.W. Hedspeth editor, Treatise on marine ecology and paleoecology. Geological Society of America. 1957; Mem67.

2. Connell J. Diversity in tropical rain forests and coral reefs. Science. 1978;199:13021310.
3. Glynn PW. High complexity food webs in low-diversity eastern Pacific reef-coral communities. Ecosystems. 2004;7:358367.

4. Graham NAJ, Wilson SK, Jennings S, Polunin NVC, Bijoux JP \& Robinson J. Dynamic fragility of oceanic coral reef ecosystems. Proceedings of the National Academy of Sciences USA. 2006;103(22) :8425-8429.

5. Ziegler $M$, Quéré $G$, Ghiglione J-F, Iwankow G, Barbe V, Boissin E, Wincker $P$, Planes S \& Voolstra CR. Status of coral reefs of Upolu (Independent State of Samoa) in the South West Pacific and recommendations to promote resilience and recovery of coastal ecosystems. Marine Pollution Bulletin. 2018;129:392398.

6. Kery M, Royle JA. Inference about species richness and community structure using species-specific occupancy models in the National Swiss Breeding Bird survey MUB. Proceedings of the 2007 EURING Technical Meeting and Workshop, Dunedin, New Zealand;2007.

7. Béguinot J. Theoretical derivation of a bias-reduced expression for the extrapolation of the Species Accumulation Curve and the associated estimation of total species richness. Advances in Research. 2016;7(3):1-16.

DOI: 10.9734/AIR/2016/26387; <hal01367803>

8. Béguinot J. Extrapolation of the Species Accumulation Curve associated to "Chao" estimator of the number of unrecorded species: A mathematically consistent derivation. Annual Research \& Review in Biology. 2016;11(4):1-19.

DOI: 10.9734/ARRB/2016/30522; <hal $01477263>$

9. Béguinot J. How to extrapolate Species Abundance Distributions with minimum bias when dealing with incomplete species inventories. Advances in Research. 2018;13(4):1-24.

DOI: $10.9734 / A I R / 2018 / 39002$

10. Brose U, Martinez ND \& Williams RJ. Estimating species richness: sensitivity to sample coverage and insensitivity to spatial patterns. Ecology. 2003;84(9):23642377.

11. Béguinot J. A new, ecologically selfsignificant metric of species-abundance unevenness, reliably highlighting the intensity of interspecific competition. 
Annual Research \& Review in Biology. 2021;36(4):48-71.

DOI: $10.9734 / A R R B / 2021 / v 36 i 430363$.

12. MacArthur $\mathrm{RH}$. On the relative abundance of bird species. Proceedings of the National Academy of Sciences U.S.A. 1957;43:293-295.

13. May RM. Patterns of species abundance and diversity. In Cody ML, Diamond JM. Ecology and Evolution of Communities. The Belknap Press of Harvard University.1975;81-120.

14. Béguinot J. Numerical extrapolation of the species abundance distribution unveils the true species richness and the hierarchical structuring of a partially sampled marine gastropod community in the Andaman Islands (India). Asian Journal of Environment and Ecology. 2018; 6(4):123.

Doi: 10.9734/AJEE/2018/41293 <hal01807454>

15. Béguinot J. The full hierarchical structuration of species abundances reliably inferred from the numerical extrapolation of still partial samplings: a case study with marine snail communities in Mannar Gulf (India). Asian Journal of Environment and Ecology. 2018;7(3):1-27. DOI: 109734/AJEE/2018/36831.

16. Béguinot J. Analyzing the role of environmental stresses on species richness and the process of hierarchical structuring of species abundances in marine Gastropods communities at Suva (Fiji Islands). International Journal of Environment and Climate Change. 2018;8(3):200-233.

17. Béguinot J. Influence of fishing activity on the total species richness and the abundance unevenness in reef fish communities: a case study in a Brazilian tropical coral complex. International Journal of Environment and Climate Change. 2019;9(1):58-76.

18. Béguinot J. Influence Analyzing the role of increasing water pollution on speciesrichness, interspecific-competition and abundance-unevenness in reef-associated fish communities, off Jakarta Bay (Indonesia). International Journal of Environment and Climate Change. 2021; in press

19. Rumohr H, Karakassis I \& Jensen JN. Estimating species richness, abundance and diversity with 70 macrobenthic replicates in the Western Baltic Sea.
Marine Ecology Progress Series. 2001;214:103-110.

20. Fontaine $B$, Bouchet $P$. et al. The European union's 2010 target: putting rare species in focus. Biodiversity and Conservation. 2007;139:167-185.

21. Flöder $S$, Jaschinski $S$, Wells $G$, Burns CW. Dominance and compensatory growth in phytoplankton communities under salinity stress. Journal of Experimental Marine Biology and Ecology. 2010;395:223-231.

22. Bracken M \& Low N. Realistic losses of rare species disproportionately impact higher trophic levels. Ecology Letters. 2012;15:461-467.

23. Mouillot D, Bellwood DR, Baraloto C, Chave J, Galzin R, Harmelin-Vivien M, Kulbicki M, Lavergne S, Lavorel S, Mouquet N, Paine CET, Renaud J \& Thuiller W. Rare species support vulnerable functions in high-diversity ecosystems. PLoS Biol. 2013;11(5): e1001569.

24. Jain M, Flynn DFB, Prager CM, Hart GM, DeVan CM, Ahrestani FS, Palmer MI, Bunker DE, Knops JHM, Jouseau CF, Naeem S. The importance of rare species: a trait-based assessment of rare species contribution to functional diversity and possible ecosystem function in tallgrass prairies. Ecology and Evolution. 2014;4(1):104-112.

25. Ignatiades L \& Gotsis-Skretas O. The contribution of rare species to coastal phytoplankton assemblages. Marine Ecology. 2014;35:132-145.

26. Low-Decarie $E$, Kolber $M$, Homme $P$, Lofano A, Dumbrell A, Gonzalez A \& Bell G. Community rescue in experimental communities. Proceedings of the National Academy of Sciences USA. 2015;112(46): 14307-14312.

27. Leitao RP, Zuanon J, Villéger S, Williams SE, Baraloto C, Fortunel C, Mendonça FP \& Mouillot D. Rare species contribute disproportionately to the functional structure of species assemblages. Proceedings of The Royal Society B. 2016;283:e0084.

DOI: $10.1098 / \mathrm{rspb} .2016 .0084$

28. Violle $\mathrm{C}$, Thuillier W, Mouquet N, Munoz F, Kraft NJB, Cadotte MW, Livingstone SW \& Mouillot D. Functional rarity: the ecology of outliers. Trends in Ecology ; 2017.

Doi 10.1016/j.tree.2017.02.002 
29. Cao Y, Williams DD, Williams NE. How important are rare species in aquatic community ecology and bioassessment? Limnology and Oceanography. 1998; 43(7):1403-1409.
30. Garcia-Callejas D. On the variability of Species Abundance Distributions with trophic guild and community structure. bioRxiv;2018. DOI: $10.1101 / 289348$

(c) 2021 Béguinot; This is an Open Access article distributed under the terms of the Creative Commons Attribution License (http://creativecommons.org/licenses/by/4.0), which permits unrestricted use, distribution, and reproduction in any medium, provided the original work is properly cited.

Peer-review history:

The peer review history for this paper can be accessed here: https://www.sdiarticle4.com/review-history/72155 